\title{
Fostering and Maintaining Responsible Conduct within Public Organiza- tions: A Case Study
}

\author{
Donovan A. McFarlane*
}

\author{
College of Business, Westcliff University, Irvine, California, United States; Huizenga School of Business, Nova South- \\ eastern University, Fort Lauderdale, Florida, United States
}

\begin{abstract}
This paper explores the need for and importance of fostering and maintaining responsible conduct in public organizations. The author uses a case study approach by looking at ethical misconduct by several board members, administrators, and managers in one of the nation's largest public school districts. Education is seen as one of the most important public goods and the need for ethically responsible conduct in educational organizations at the public school district and school board levels underscores the important role of an institution seen as vital to ethical progress, well-being, and posterity. The causes of ethical failure are explored from the perspective of leadership and culture, and the author recommends strong ethical and strategic leadership, trust-building, and ethical monitoring as important steps toward fostering and maintaining ethical conduct in the particular case in question, and for public organizations in general.
\end{abstract}

Keywords: Ethical leadership, public good, public service motivation (PSM), strategic leadership, trust-based model, trustbuilding.

\section{INTRODUCTION}

Public organizations are the gateway to our collective interests and our future, and how effectively and efficiently they function in accomplishing their goals, missions, and objectives will determine how well we live, the freedom we enjoy, among other factors. Those that are especially essential to collective outcome in the form of what Gergen [1] describes as the "common good" is especially pivotal in shaping how we think about the roles of public organization in an era of leadership and public administration crisis, where cities and public organizations are grappling with financial-economic, social, political, legal and other challenges that constrain their resources and their ability to keep up with accountability standards and the increasing needs of a diverse and more difficult to manage citizenry. Managers of our public organizations must be ethical for us to have good government and good governance [2]. This means doing what is right and getting things done right, since as Menzel [2] seems to imply, we cannot expect to have ethical and efficient public organizations with ethically and morally mute managers. Therefore, despite a great tendency toward ethical and moral relativism [3, 4], we still need to look toward public officials to maintain a high standard within public organizations, as well as on a personal and professional level.

\section{RESPONSIBLE CONDUCT IN PUBLIC ORGANIZA- TIONS}

The $21^{\text {st }}$ century is a remarkable one with extraordinary challenges and problems, especially on an ethical level when

\footnotetext{
*Address correspondence to this author at the College of Business, Westcliff University, Irvine, California, United State, Huizenga School of Business, Nova Southeastern University, Fort Lauderdale, Florida, United States; Tel: 954-262-5162; Fax: 954-262-3974:

E-mails: donovan@nova.edu; donovanmcfarlane@westcliff.edu
}

it comes to responsible conduct within our public organizations. The media is filled with disturbing reports of leaders and public servants on all levels engaging in conducts - unethical and immoral behaviors and actions that are not only repugnant to the principles and virtues of our democracy, but also to the very professions and public roles they play that so impact communities and our future. One such public organization is the typical American public school district, generally headed by a superintendent and several elected board members. Education has become overly important to the economic and global competitiveness of nations and will become even more so in the future. This is why Ladner, LeFevre, and Lips [5] describe our present era as one characterized by an "education arms race' in which nations are increasingly recognizing how this public good shapes their global competitive advantage and future. For example, students' performance in the areas of mathematics, science, and technology has a significant impact on economic growth [6]. Thus, education is a public good that affects our current and future well-being and effective leadership and management of the public administration shaping our education is essential in accomplishing this. One of the most fundamental requirements in education success and competitiveness is having ethical and conscientious leaders and managers in our public school systems who care about what they do and fully appreciate how their behaviors and conducts can impact our current well-being and future through educational attainment.

\section{CASE ANALYSIS: THE BROWARD COUNTY PUB- LIC SCHOOLS AND SCHOOL BOARD}

The most fundamental public organization responsible for ensuring educational progress and success in a community or society is the public school board or public school district system, which is generally run by a group of public administrators as both appointed and elected members. This 
includes mainly superintendents, board members, and principals. The School Board of Broward County, located in Broward County in South Florida, is one of the largest public school district in the United States.

From the School Board of Broward County's website, we can see that this public organization goes back as far as the 1900s. As related from the School Board, the Broward County School District was established in 1915. With its establishment, "The Superintendent, a three-member Broward County Board of Public Instruction, and elected trustees of each school guided the county's schools [and] the first Superintendent of Broward County Public Schools was J.M. Holding, and the first Board Chairman, C.D. Kittredge" [7]. By the year 1983, total enrollment in the Broward County Public School system had reached 124, 895, by 2003, 266, 272 students [7]. As of 2014, Broward County Public Schools as led and managed by the School Board of Broward County has 238 schools, centers, and charter schools and is designated the sixth largest school district in the nation, and is also the largest fully accredited school district in the country. According to the Broward County Public Schools [8], the school district has students from 204 different countries who speak 135 different languages; it is a very diverse public organizations and its significant level of diversity represents part of the challenge that its public leaders and managers must effectively and efficiently deal with while meeting increased calls and demand for accountability - financially, ethically, and academically.

The public administrators who are responsible for the smooth and successful operations of the Broward County School District comprise the School Board of Broward County, which consists of the superintendent and nine board members. Furthermore, at the district level, there are area superintendents responsible for district divisions such as North Area, Central Area, and South Area (the three district divisions of the Broward County Public Schools). The current superintendent is Robert W. Runcie, who took over from James Knotter, who was leading what turned out to be one of the most unethical and chaotic school districts and public organizations in Florida and the country up until 2011 when Runcie took over the role. When James Knotter resigned as superintendent, the school board and district were involved in many scandals, was indicted by a state grand jury, experienced the arrests of two School Board members, and years of labor disputes with the Broward Teachers Union were getting more severe and relationships strained.

\section{Organizational Code of Ethics}

The School Board of Broward County has an extensive ethical policy which governs the conduct and behavior of its board members. Despite the existence of this "Ethics Code for School Board Members" [1007, http://www.broward.k12.fl.us/ sbbcpolicies/docs/p1007.000.pdf], there has been so many ethical violations that the State of Florida at the government's order had to initiate grand jury investigation of the School Board of Broward County in 2011-2012. The purpose of the "Ethics Code for School Board Members" is as follows:

The purpose of this policy is to create a culture that fosters public trust and confidence in government in general and
The School Board of Broward County, Florida ("The School Board") and avoids conflicts of interest and appearances of impropriety [9].

This extensive code of ethics for Broward County School Board members conforms with applicable federal, state, and local laws, and the "Standards of Conduct" enumerated are consistent with the following sections of Florida Statutes: (a) The Code of Ethics for Public Officers and Employees Chapter 112, Part III, Florida Statutes, as interpreted by the Florida Commission on Ethics; (b) Chapter 838, Florida Statutes, concerning Bribery; Misuse of Public Office; (c) Chapter 839, Florida Statutes, concerning Offenses by Public Officers and Employees; (d) Title 18 - 63 U.S.C. Section 1341, et seq. concerning Mail Fraud and Other Fraud Offenses; (e) The Ethics in Education Act, Chapter 2008- 108, Laws of Florida; and (f) The Florida Code of Ethics for the Education Profession, Sections 6B - 1.001 and 6B - 1.006, Florida Administrative Code [9]. The extensive code further deals with acceptance of gifts, relationship with lobbyists, relatives, principals, classification of misuse of office, among other issues. A copy of the Code of Ethics for School Board Members can be found here: [http://www.broward.k12.fl.us/sbbcpolicies/docs/p1007.000. pdf]. Furthermore, Broward County School Board members as public officials and employees must live up to Florida Code of Ethics.

\section{ETHICAL PROBLEMS AND CHALLENGES}

Over the past several years, Broward County Public Schools and its Board have been involved in numerous unethical practices and public scandals that threatened the face of public education in the county and eroded trust and confidence in the organization. The most extensive chronicling of these ethical violations by school board and school district members can be found in the report titled "Final Report of the Nineteenth Statewide Grand Jury in the Supreme Court of the State of Florida, Case No: SC 09-1910."

According to the extensive report on the ethical violations of the School Board of Broward County, public school district members and employees, testimonies and statements confirming gross ethical violations and unethical practices were derived from

FDLE investigators, project managers and building inspectors from the District, as well as past and present managers from the Facilities department, District Chief Building Officials, past and present Board Members, numerous District Budget and Finance officials, past and present employees of the District's boundaries department, Deputy Superintendents and other District employees from principals to secretaries [10].

The report characterized the conduct of senior management at Broward County Public Schools, including board members as engaging in gross mismanagement of the organization, citing "corruption of our officials by contractors, vendors and their lobbyists" [10] as a major problem, and many of the ethical problems and problems of corruption were described as longstanding. Furthermore, the Grand Jury investigation cited the School Board and district as engaging in a culture lacking discipline, and one where fear prevailed 
as mid-level managers were not able to discipline or fire incompetent workers, and efforts to resolve ethical and managerial challenges were

Thwarted by a timid personnel department and sometimes by protective Board members who must vote on every dismissal, yet [there is awareness] of top level managers who openly talk of targeting whistle blowers, boat-rockers and other malcontents whose primary sin appears to be exposing flaws in the system and lack of leadership among senior staff [10].

Further ethical violation in the Broward County Public School district included unwarranted transfer of workers to what were designated "districts dumping grounds" such as the book depository, and some were simply fired for petty violations [10]. Some of the direct violations included the acceptance of bribes, and in several cases board members were arrested by federal authority for accepting such bribes for public school district contracts. Furthermore, the Statewide Grand Jury in its report lamented that present in the school district was a

Middle management staff that tolerates or is forced to tolerate incompetence, double-dealing, corruption and laziness but which in turn is always fearful of being targeted by upper management should they challenge interference by Board members or attempt to hold contractors accountable for their work [10].

Most discouragingly, the report deemed the ethical and general problems with the school district Board as even worse as demonstrated by lack of leadership and awareness and there was a presence of unqualified board members, whose ethical violations and corrupt practices included selecting building contractors, deciding contract methods, interfering with personnel decisions, directing contracts to friends and acquaintances for consulting work, pushing unnecessary building projects in direct opposition to the advice of district officials, lobbying for construction change orders to benefit contractors, and even things as petty as manipulating the process to get the children of friends and family into specific schools [10]. According to the report, because the Board was caught up in district-wide micromanaging it failed to lead and authorized the spending of billions of dollars over a 10 years period, leaving Broward County taxpayers with over $\$ 2$ billion in long-term debt and thousands of empty seats at under-enrolled schools.

Apart from the above violations, there were incidences of receiving gifts from multiple donors, failure to reports gifts received and accepted, breach of confidentiality, silencing of critics and potential whistleblowers by threats, voting conflicts in terms of personal interests, self-serving behaviors, and collusion among senior district members to stall reports and other activities [10].

\section{REASONS FOR ETHICAL FAILURE}

Ethical failure in any organization can be linked to leadership and management, and public organizations are no different. Leaders and managers in public organizations are supposed to maintain ethical standards and ensure that their organizations and employees, agents, or business associates act in accordance with applicable federal, state, and local laws when conducting business. In the case of the Broward County Public School district and its Board, this was not the case as the many ethical violations as reported by the State of Florida Grand Jury, resulted from ineffective and corruptive leadership and management. Organizations need ethical leaders and managers in the $21^{\text {st }}$ century [2], and this leadership and management cannot be ethically or morally mute [2] or we will witness the extensive ethical violations and moral chaos that have forever tainted the history of the Broward County School Board.

Another important factor in ethical failure is organizational culture, especially as the values, behaviors, and practices in an organization are influenced by leadership or management's values. Some organizations have strong ethical cultures while others have exactly the opposite. If ethics is to be seen as important in an organization it must be something that is valued by leaders and managers. Moreover, leaders and managers must actively demonstrate ethical behaviors by setting examples and underscoring its importance to the overall mission and vision of the organization. Ethical cultures are purposeful and must be built on strong values and the conviction that ethics matters, and that ethical success is as important as financial success to businesses and organizations. Whether public school districts and school boards, or other public organizations, these organizations must see their mission and vision embedded in socially responsible actions and behaviors that are ethical and in the best interest of the individuals and communities they serve. Building an ethical culture requires commitment to doing the right thing and it should become both a value and a process.

\section{THREE-FOLD SOLUTION TO FOSTERING AND MAINTAINING ETHICAL CONDUCT}

Based on how extensive the ethical problems have been in the Broward County Public Schools and with the School Board of Broward County, there seems to be three major requirements for fostering and maintaining responsible conduct in this public organization: effective ethical and strategic leadership, more stringent and regular monitoring by the State of Florida under applicable statutes concerning ethics and public interests, and the development of an ethical culture based on a perception that a culture of unethical behavior has defined the school district from the top or its executives (the school board) right down to the school level including school building personnel and even lay-staff members. A culture of ethics with strong ethical and strategic leadership and internal controls by leaders and managers and external controls through the state mechanism must become part of the solution to fostering and maintaining ethical conduct in Broward County Public Schools.

\section{Leadership}

Ethical leadership is a primary recommendation for increasing responsible conduct in public organizations. Leadership in organization is essential in planning the future and looking at the big picture of the organization both within industry and societal constructs [11]; strategic leadership matters on all levels because it shapes the culture, strategy, business model and other factors pertaining to how effectively the organization carries out its mission and meets the 
needs and expectations of all stakeholders. Public school district systems have a mission that is essentially larger than the organization itself because they are invested with educating a workforce and citizens in accordance with society's needs. This means that leaders and administrators of school districts as public officials must rethink their organizations given current demand for increased accountability and ethical practices; they must now integrate ethics into their broad vision. Public organizations have ethical obligations to act responsibly and foster responsible conduct in performing their roles and functions as part of public trust. School Board members must increasingly see themselves as strategicethical leaders guided by what Shapiro and Stefkovich [12] describe as the "ethics of the profession" or professional ethics defining their particular roles and responsibilities and modes of conduct under private and public administrative agency principles and requirements.

\section{State Ethical Monitoring}

The State has the most powerful vested interest in the activities and success of public organizations because they are the mechanisms through which states accomplish their public mission and vision. Therefore, the State must always implement effective monitoring processes and tools to ensure compliance with laws, policies, rules, regulations and all standards of conduct and ethics. The State of Florida's Code of Ethics (ss. 112.311-112.326) governs the conducts of public officers and employees and board members in the Public School District [13]. According to the Statewide Grand Jury, the conducts by Broward School Board members and administrators have violated Florida Statues by not living up to the standards described under Chapter 112 - Public Officers and Employees, General Provisions, Part III, "Code of Ethics for Public Officers and Employees (ss. 112.311-112.326)." Public officers and employees must act in good ethical faith in carrying out their duties and responsibilities. This will require closer monitoring and oversight by State mechanisms in Broward County Public Schools since County-level monitoring has failed to prevent the many gross unethical practices of the past. The recommendation of the Statewide Grand Jury that the School Board employs an Inspector General for monitoring ethics will also require an external enforcement authority under the jurisdiction of the State of Florida to work effectively.

\section{Build Stronger Culture of Ethics and Trust: A Culture Problem?}

Unethical practices are often connected with organizational ethical climate and culture, and thus, there is a need to embed strong ethical values in organizational culture. Public organizations can be rigid bureaucratic entities where low cultural assimilation of members takes place because of the emphasis on rules and policies that do not necessarily build an empowerment and trust mechanism for acting ethically [14]. The School Board of Broward County needs to rebuild the culture to eliminate the mistrust and ethical malpractices and misconduct left behind by its former leaders and board members who created an atmosphere of declining ethical culture up to the year 2011 when most of the complaints had reached their peak, resulting in a grand jury declaration and recommendation to the State of Florida and the prosecution of several board members and administrators and resignation of the school superintendent. Organizations where ethical values, actions, and behaviors are not emphasized will naturally experience a culture hostile to ethical compliance and the School Board of Broward County seems to have been an organization with such a culture.

\section{RECOMMENDATION FROM STATE OF FLORIDA STATEWIDE GRAND JURY}

The recommendations by the Statewide Grand Jury in its report should be more than sufficient to set a credible foundation on which the School Board of Broward County can rebuild an ethical reputation, and so far, the new superintendent Robert W. Runcie seems to be leading the district and board toward this end. Some of the recommendations made by the Statewide Grand Jury should ensure ethical selfmonitoring if adhered to. For example, the following recommendations are especially significant: refuse campaign contributions from contractors, vendors and others doing business with the Board; require mandatory ethics training and testing by an outside agency; and all late additions to the Board's agenda must be discussed at a public meeting [10].

Several other sensible recommendations to lesson the occurrence of future ethical problems in Broward County Public School district and among the Board members also included creating an independent office of Inspector General to monitor the Board and District, removing all involvement by Board members in the selection of contractors, vendors, or financial institutions, and prohibiting gifts of any value to any Board member or District employee from anyone doing business with the District or lobbying the Board [10].

\section{STRATEGIC RECOMMENDATIONS FOR RESPON- SIBLE CONDUCT IN PUBLIC ORGANIZATIONS}

Government organizations and public workers and officials perform very important functions and how effectively they organize and manage these organizations affect the well-being of the communities and nations they serve [15]. Therefore, the increased demand for ethical and responsible conduct in public organizations is no coincidence or imposition, but a legitimate concern of the public whose well-being and investment are at stake when public officials engage in corrupt and all other forms of unethical behaviors and activities.

According to O'Toole Jr. [16], public administration increasingly takes place in environments or settings of networked actors who essentially rely on each other and cannot compel compliance on the part of others. The interaction between and among public workers and other parties affects the degree to which responsible conduct is embraced and followed. Therefore, responsible conduct must be enforced internally and externally; that is, using both internal and external controls to monitor and compel ethical decisions and actions by strictly regulating the behaviors and interactions of public personnel or public officials.

The most apparently ready and credible solution to the ethical challenges and problems of public organizations seems to be leadership - ethical and strategic leadership - a form of leadership that fosters ethical conduct by emphasiz- 
ing ethics as an overarching part of the broader mission and vision of public organizations. After all, public organizations including public school districts and public school boards are not simply mechanisms of necessity in a capitalistic society, but part of the broader mandatory and indispensible frame of social order and the political-social-economic systems that keep a society intact and free from the kind of anomie described by French sociologist Emile Durkheim. Leadership matters in public organizations, and perhaps even more so than in private organizations where they too are focused on leadership as the solution to all organizational problems and challenges. Public organizations such as the Broward County Public Schools need strong ethical leadership and it is the responsibility and role of the School Board of Broward County to provide such leadership.

Pointing to effective ethical and strategic leadership as the solution to organizational challenge is not a cliché prescription or recommendation, but one which is a salient requirement for any entity wherein the behaviors, values, actions, attitudes and decisions of its members represent the most powerful variables influencing affect and effect - outcomes and perceptions for everyone involved, and most importantly, the public. The recommendation of strong and effective ethical and strategic leadership is supported by Jas and Skelcher [17] as they argue in regard to public organizational challenges, that the "strategies applied are principally concerned with building a leadership capability that engages senior politicians and managers" (p. 195), and these strategies must be carefully aligned with the ethical expectations and values of all stakeholders.

Grundstein-Amado [18] argues for the application of bilateral transformational leadership approach to foster ethical conduct in public organizations. This approach consists of the processes of self-discovery and reflection. GrundsteinAmado [18] describes this approach as follows:

This approach permits influences and definitions of organizational goals and ethical conduct to be jointly shaped by both leaders and followers. Bilateral transformational leadership directs leader and follower to jointly construct a common values framework that serves as a basis for establishing a collective vision of change through meaningful and responsible actions. A shared moral reasoning process exercised by leader and followers reinforces the bilateral transformational process and consequently elevates and improves the ethical conduct of members in the public service organization (p. 247).

This makes sense since ethical conduct in an interactive environment does not solely rest on the decisions, actions, and behaviors of a single individual. Even in cases where specific individuals are highly ethical and highly morally conscientious, they can only do so much to ensure ethics prevail, perhaps limited to controlling their own ethical behaviors and not those of others as O' Toole Jr. [16] argues.

The view that leadership is perhaps the most critical factor in ensuring and fostering responsible conduct in public organizations is further supported by Nutt and Backoff [19]. They argue that public organizations can be effectively transformed through strategic leadership and strategic management. Just like the strategic leadership and management process that ask critical and key questions about private or- ganizations, public organizations must undertake the same process, and a key question in this is consideration of vision, and most importantly, an ethical vision or vision for ethical role and responsibility in communities and society. Thus, Nutt and Backoff [19] argue that strategic leaders in public organizations must direct their energies into shaping current policies and issues toward building better and more ethical organizations focused on serving the needs of communities. Education is an important and necessary public good and the Broward County Public Schools and its Board must engage strategically responsible leadership to ensure that ethical conduct prevails at each level of the school system.

A critical role played by all leaders and managers in organizations becomes important to encouraging and fostering responsible conduct in public organizations. This is the role of motivating followers and subordinates or employees and associates. Public administrators must motivate others to be ethically responsible in their actions and behaviors. This means that public leaders and managers must ensure that all other coordinates or variables of a workplace with high morale exist within their organizations. This is supported by the literature. As Pandey, Wright, and Moynihan [20] note, "A good deal of research has demonstrated how public service motivation (PSM) facilitates desirable organizational attitudes and behaviors such as job satisfaction, organizational commitment, and work effort" (p. 89). Furthermore, effective public service motivation (PSM) will certainly facilitate more responsible ethical conduct as public workers or employees whose needs are adequately met with have less inclination and tendency to engage in questionable acts including bribery, corruption, and the like. The school superintendent and School Board of Broward County need to consider how they can effectively motivate their staff and administrators and workers to be ethical stewards for their organization, and they must model the way by setting examples. As Kouzes and Posner [21] note, exemplary leadership is needed and these leaders model the way and encourage the hearts of their followers to act in ways beneficial to the organization and its publics.

Leaders and managers in public organizations can also encourage more responsible conduct by increasing trust among themselves and their followers and subordinates. $\mathrm{Ny}$ han [14] suggests applying a trust-based organizational paradigm to this end. This will certainly increase responsible conduct as "participation in decision making, feedback from and to employees, and empowerment of employees lead to increased interpersonal trust (between supervisor and employee) in a public organization" [14, p. 87]. Furthermore, Nyhan [14] argues that, "trust-building practices between supervisors and workers can lead to increased productivity and strengthened organizational commitment" (p. 87), and thus, a "trust-based model is a viable paradigm for increasing interpersonal trust, organizational commitment, and productivity in the public sector" [14, p. 87]. This means that public leaders and managers need to use this trust-based model to get buy-in from their public subordinates as far as code of ethics and ethical standards are concerned in organizations. Committed and satisfied workers are more inclined to follow organization standards of care out of obligation and loyalty attachments. The implications of this for a public organization like the Broward County Public Schools and the School 
Board of Broward County include the following: (a) in order for there to be ethical practice throughout the public school district employees must feel a sense of empowerment and responsibility to do the right thing; (b) leaders and managers in the public school board and system must model the way by demonstrating examples of ethical behaviors; (c) a new organizational value of commitment and responsibility must be communicated by leaders and managers; and (d) increased commitment to building trust and ensuring worker satisfaction in the school district can renew employee dedication toward doing the right thing.

While Denhardt [22] argues that there is no clear consensus on what constitutes ethical administrative behavior, or whether concern should lie with corrupt practices, administrative role in policy-making processes, the conflicting obligations of public administrators, or other associated issues, it is sufficiently clear that public ethics is an area of significant vested interest as public administrators affect the well-being and lives of citizens. Thus, they must act morally, ethically, and conscientiously and must focus obsessively on meeting the needs of the public as expected by all stakeholders. Our public organizations are the pendulums on which a prosperous society and future swing. Therefore, it is important that the School Board of Broward County recognize the imperative of its members as public officials and public employees who must act in the highest ethical manner as they preserve public trust in meeting their mission and vision. Finally, ethical compliance requires third-party monitoring, and having a mechanism of monitoring by the State or other external bodies is critical in fostering and maintaining responsible conduct in Broward County Public Schools and its School Board. As Cooper [23] notes, "there are two general approaches to maintain responsible conduct within public organizations: internal and external controls" (p. 149), and this principle needs to become the norm for ethical public organizations - fostering more internal and external ethical controls.

\section{CONFLICT OF INTEREST}

The author confirms that this article content has no conflict of interest.

\section{ACKNOWLEDGEMENTS}

Declared none.

\section{REFERENCES}

[1] Gergen D. Ethics, government and the common good [Video]. Chautauqua Institution 2012. Available from https://www.youtube.com/watch?v=2Udy8_HKOeE [cited $2^{\text {nd }}$ Oct 2014].

[2] Menzel DC. Ethics management for public administrators: Leading and building organizations of integrity, $2^{\text {nd }}$ ed. Armonk, New York: ME Sharpe 2012.

[3] Murphy P, Laczniak G, Bowie N, Klein T. Ethical marketing. Upper Saddle River, NJ: Pearson Education, Inc 2005.
[4] Murphy P, Laczniak G. Marketing ethics: cases and readings. Upper Saddle River, NJ: Pearson Education, Inc 2006.

[5] Ladner M, LeFevre AT, Lips D. Report card on American education: Ranking state K-12 performance, progress, and reform. $16^{\text {th }}$ ed. Washington, DC: American Legislative Exchange Council: ALEC 2010. Available from http://www.alec.org/AM/ pdf/education/2010_reportcard/finalcopycondensed.pdf [cited 2nd Oct 2014].

[6] Hanushek EA, Woessmann L. Economic quality and economic growth. Washington, DC: The International Bank for Reconstruction and Development/The World Bank 2007.

[7] Broward County Public Schools. The history of Broward County Public Schools. Broward County Public Schools 2010. Available from http://bcps.browardschools.com/history/1899.htm [cited 2nd Oct 2014].

[8] Broward County Public Schools. About Broward County Public Schools. Broward County Public Schools 2014a. Available from http://www.browardschools.com/ About-BCPS [cited 2nd Oct 2014].

[9] Broward County Public Schools. Ethics code for School Board members. Broward County Public Schools 2014b. Available from http://www.broward.k12.fl.us/ sbbcpolicies/docs/p1007.000.pdf [cited 2nd Oct 2014].

[10] The Supreme Court of Florida. (n.d.). "Final report of the Nineteenth Statewide Grand Jury in the Supreme Court of the State of Florida, Case No: SC 09-1910.” Available from http://www.floridasupremecourt.org/pub_info/summaries/briefs/09/ 09-1910/Filed_02-18-2011_Final_Report.pdf [cited 2nd Oct 2014].

[11] De Kluyver CA, Pearce II JA. Strategy: a view from the top, Fourth edition. Upper Saddle River, New Jersey: Prentice Hall 2012.

[12] Shapiro JP, Stefkovich JA. Ethical leadership and decision making in education: applying theoretical perspectives to complex dilemmas, $2^{\text {nd }}$ ed. New Jersey: Lawrence Erlbaum Associates, Inc 2005.

[13] Florida Statutes. (n.d.). Chapter 112: Public Officers and Employees: General Provisions, Part III "Code of Ethics for Public Officers and Employees (ss. 112.311-112.326)." Available from http://www.ethics.state.fl.us/ethics/Chapter_112.html [cited 2nd Oct 2014].

[14] Nyhan RC. Changing the paradigm trust and its role in public sector organizations. Am Rev Public Adm 2000; 30(1): 87-109.

[15] Rainey HG. Understanding and managing public organizations. San Francisco: John Wiley \& Sons 2009.

[16] O'Toole J, Laurence J. Treating networks seriously: Practical and research-based agendas in public administration. Publ Admin Rev 1997; 57(1): 45-52.

[17] Jas P, Skelcher C. Performance decline and turnaround in public organizations: a theoretical and empirical analysis. $\mathrm{Br} \mathrm{J}$ Manage 2005; 16(3): 195-210.

[18] Grundstein-Amado R. Bilateral transformational leadership: an approach for fostering ethical conduct in public service organizations. Admin Soc 1999; 31(2): 247-60.

[19] Nutt PC, Backoff RW. Transforming public organizations with strategic management and strategic leadership. J Manage 1993; 19(2): 299-347.

[20] Pandey SK, Wright BE, Moynihan DP. Public service motivation and interpersonal citizenship behavior in public organizations: Testing a preliminary model. Int Publ Manage J 2008; 11(1): 89108.

[21] Kouzes JM, Posner BZ. The leadership challenge, $3^{\text {rd }}$ ed. San Francisco: Jossey-Bass Publishers 2002.

[22] Denhardt KG. The ethics of public service: Resolving moral dilemmas in public organizations (No. 195). Westport, Connecticut: Greenwood Publishing Group 1988.

[23] Cooper TL. The Responsible administrator: An approach to ethics for the administrative role, $5^{\text {th }}$ ed. San Francisco: John Wiley \& Sons 2006 